\title{
Correction to: Mobilizing private adaptation finance: lessons learned from the green climate fund
}

\author{
P. P. Stoll ${ }^{1}$ - W. P. Pauw ${ }^{2,3,4,5}$ (D) F. Tohme ${ }^{6} \cdot$ C. Grüning ${ }^{2}$
}

Published online: 1 February 2022

(C) Springer Nature B.V. 2021

\section{Correction to: Climatic Change https://doi.org/10.1007/s10584-021-03190-1}

In the original publication, author P.P. Stoll was incorrectly linked to all the affiliations on the paper. The original publication has been corrected.

Publisher's note Springer Nature remains neutral with regard to jurisdictional claims in published maps and institutional affiliations.

The online version of the original article can be found at https://doi.org/10.1007/s10584-021-03190-1

W. P. Pauw

w.p.pauw@gmail.com

1 Independent Consultant, Frankfurt am Main, Germany

2 Frankfurt School of Finance \& Management, Adickesallee 32-34, 60322 Frankfurt am Main, Germany

3 Copernicus Institute of Sustainable Development, Utrecht University, Utrecht, The Netherlands

4 Stockholm Environment Institute, Stockholm, Sweden

5 German Development Institute, Bonn, Germany

6 Leibniz Institute for Financial Research Safe Frankfurt, Frankfurt, Germany 